\title{
Age, Growth, Maturity, and Spatial Distribution of Bluefish, Pomatomus saltatrix (Linnaeus), off the Northeast Coast of the United States, 1985-96
}

\author{
Daniel J. Salerno \\ Northeast Fisheries Science Center, National Marine Fisheries Service, NOAA \\ 166 Water Street, Woods Hole, Massachusetts 02543, USA \\ Jay Burnett \\ Northeast Fisheries Science Center, National Marine Fisheries Service, NOAA \\ 166 Water Street, Woods Hole, Massachusetts 02543, USA \\ Richard M. Ibara \\ University of Massachusetts - Dartmouth, Department of Biology \\ 285 Old Westport Road, North Dartmouth, Massachusetts 02747, USA
}

\begin{abstract}
Bluefish, Pomatomus saltatrix, are distributed worldwide and found regionally along the eastern United States in the Gulf of Mexico and from Florida to Maine. The species supports a major recreational fishery and to a lesser extent a seasonal commercial fishery in NAFO Divisions 5 and 6. The ages of 3334 bluefish were determined using scales from bluefish collected off the U.S. northeast coast during Northeast Fisheries Science Center autumn bottom trawl surveys in 198596, a period within which bluefish abundance decreased substantially. This study used length and age data to estimate growth rates by sex and by year. Maturation patterns were examined for the period 1993-96. The autumn geographical distribution of age-classes 0, 1, 2 and 3+ fish was also analyzed.

The oldest bluefish in the study was twelve years old and the largest was $88 \mathrm{~cm}$ (fork length). No significant differences were found in growth between sexes or on an inter-annual basis; von Bertalanffy growth parameters for both sexes and all years combined were $L_{\text {inf }}=87.2 \mathrm{~cm}, k=0.26$ and $t_{0}=-0.93$. Incremental growth rates in length showed a significant decrease after the age of two. The median length at maturity was $33.9 \mathrm{~cm}$ for males and $33.4 \mathrm{~cm}$ for females. The median age at maturity was 1.2 and 1.1 years for males and females, respectively. Younger fish were almost always found inshore and older age-classes tended to be found mostly offshore.
\end{abstract}

Keywords: age, bluefish, distribution, growth, maturity, Pomatomus saltatrix

\section{Introduction}

Bluefish, Pomatomus saltatrix, occur in temperate and warm temperate zones throughout the world and are generally found in continental shelf waters (Briggs, 1960). Its distribution in the Indian Ocean includes the east coast of southern Africa, Madagascar, the Malay Peninsula, Tasmania, and the southern and western coasts of Australia. In the eastern Atlantic Ocean, distribution ranges from Portugal to Senegal, including the Azores, the Mediterranean and Black Seas, and from Angola to South Africa (Briggs, 1960). In the Western Atlantic, its known range includes the
Gulf of Mexico and the eastern coasts of North and South America, encompassing regularly the region northward from Florida to Cape Cod, MA and occasionally to Nova Scotia, and southward to Brazil and Argentina (Bigelow and Schroeder, 1953). Off the northeast coast of the U.S., bluefish support important seasonal recreational and commercial fisheries in NAFO Divisions 5 and 6 (NEFSC, MS 1997).

Bluefish travel in large, loosely aggregated groups of like-sized fish (Wilk, 1977). Along the U.S. Atlantic coast, movements of this migratory pelagic species 
appear to be regulated by water temperature. During the spring migration, they travel northward and inshore to the region north of Cape Hatteras, NC, to Cape Cod, MA, briefly moving offshore in the late spring and summer months to spawn (Kendall and Walford, 1979). The autumn migration of bluefish begins with decreasing water temperatures when they move to the relatively warmer waters both offshore and along the southeast coast of the U.S. (Lund and Maltezos, 1970). While it is generally considered that there are spring-spawning and summer-spawning contingents of bluefish (Lassiter, MS 1962; Wilk, 1977; Nyman and Conover, 1988; Chiarella and Conover, 1990, McBride and Conover, 1991), Hare and Cowen (1993) presented evidence that bluefish spawn from March to September, and that the appearance of spring- and summer-spawned cohorts is a product of larval transport mechanisms within the region.

Age and growth studies have been conducted in various regions of its distribution: Hamer (1959) studied bluefish from the New York Bight, Lassiter (MS 1962) from North Carolina, Richards (1976) from Long Island Sound, Wilk and Walford (unpublished data; reported in Wilk, 1977) from Florida to Rhode Island, and Barger (1990) from the Gulf of Mexico and the U.S. south Atlantic coast. Few studies of reproductive biology exist: Lassiter (1962) estimated fecundity of 10 bluefish from North Carolina; Finucane et al. (1980) described spawning in the Gulf of Mexico, and Chiarella and Conover (1990) examined maturity stages and derived gonadosomatic indices in the Mid-Atlantic Bight to address spawning seasonality.

The main purpose of this study was to conduct a temporally and spatially synoptic age and growth study of bluefish off the northeast coast of the U.S. during a period, 1985-96, in which spawning stock biomass and landings decreased by about $60 \%$ and $75 \%$, respectively (NEFSC, MS 1997). The growth and maturation rates during this period were examined for evidence of any compensatory response to decreased abundance, i.e. increases in growth or maturation at an earlier age. Additionally, autumn distribution was analyzed by age-class in order to evaluate the hypothesis that larger bluefish have been displaced offshore and are not readily available to recreational and commercial fisheries as they were in the past (Crecco, MS 1996).

\section{Materials and Methods}

Data analyzed in this study were collected from 1985-96 during Northeast Fisheries Science Center (NEFSC) autumn research vessel bottom trawl surveys. Details regarding survey design, area, timing, gear and sampling methodology were described by Azarovitz (1981). All bluefish were measured at fork length to the nearest centimeter. Fish selected for age sampling were sexed and assigned a maturity stage based on macroscopic examination of gonads (Burnett et al., MS 1989). Maturity stages were described as follows: immature (has not yet spawned), developing (will spawn in current season), ripe (actively spawning), spent (spawning completed), and resting (mature but no current gonadal activity) (O'Brien et al., 1993). Several scales were removed from the pectoral fin region and stored dry in envelopes. Prior to 1992, age sampling protocol required ten fish from the length interval $0-15 \mathrm{~cm}$, fifteen fish from 16-30 $\mathrm{cm}$, twenty fish from $31-45 \mathrm{~cm}$, and all fish greater than $45 \mathrm{~cm}$ per six hour watch; since 1992, one fish was sampled per centimeter per trawl station.

Scales were pressed onto laminated plastic slides with a hand roll press to form permanent impressions (Penttila et al., 1988). These impressions were viewed with an Eberbach scale reader at $43 \mathrm{x}$ magnification for age determination, which consisted of enumerating the number of annuli present. Annuli, which are laid down each spring (Wilk, 1977), are defined as "a band of widely spaced circuli, usually with broken circuli in the anterior field and/or anastomosis (crossing over) in the lateral field, followed by a series of closely spaced circuli" (Barger, 1990) (Fig. 1). The validity of scale annuli was reported by Wilk (1977) and Barger (1990), based upon marginal increment analysis, recapture of tagged fish, and aquarium specimens, and comparisons with otoliths and vertebrae, respectively.

Growth rates for bluefish were expressed in terms of a semi-logarithmic regression model:

$$
\text { length }=a+b \times \ln (\text { age })
$$

This model was chosen for its properties with respect to statistical comparisons (Bowering and Brodie, 1984; Bowers, 1960). The model was fitted to mean length at age data for male and female bluefish for all years combined and for combined sexes on an annual basis. The use of mean lengths was 


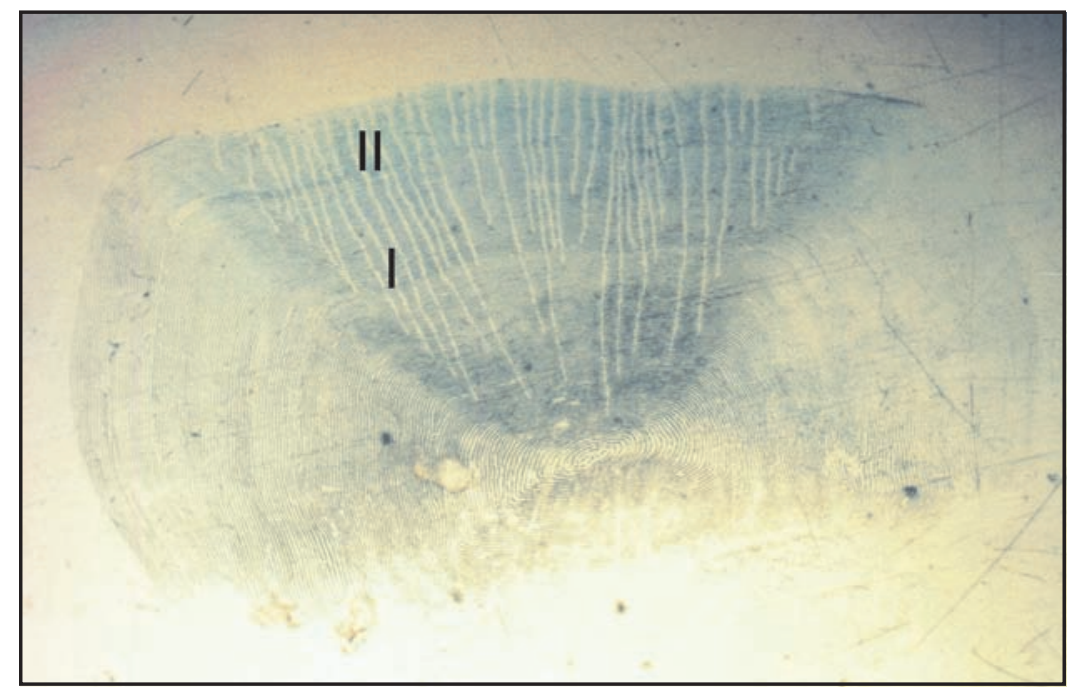

Fig. 1. Scale from a 2+ year old bluefish, $52 \mathrm{~cm}$ fork length, captured in the autumn of 1985 .

necessary due to the preponderance of age 0 and age 1 fish as well as the scarcity of fish at older ages. Each mean length was weighted equally in the resulting regressions. Bluefish that were immature and sex unknown were incorporated into both male and female growth analyses. Comparisons of growth rates by sex and by year were performed using a test for heterogeneity of slopes (Sokal and Rohlf, 1995).

Von Bertalanffy growth equations (von Bertalanffy, 1938) of the form:

$$
L_{t}=L_{i n f}\left(1-e^{-k\left(t-t_{o}\right)}\right)
$$

were derived for bluefish to provide estimates of $L_{\text {inf }}$ (theoretical asymptotic length), $k$ (Brody growth coefficient), and $t_{0}$ (the hypothetical age of zero length). The procedure SAS NLIN, an iterative, least squares, nonlinear regression procedure (SAS, 1988), was used for parameter estimation.

Maturity at length and age data from 1993-96 were analyzed using probit analysis (Finney, 1971). These years were chosen as the most recent in the study period, and for the fact that the length-stratified sampling protocol during this period was superior statistically for maturity analyses than that in 1992 and before (Morgan and Hoenig, 1997). Bluefish for which the sex was undetermined were added in equal proportion to both male and female data. Maturity at length and age ogives were constructed for each sex, and goodness of fit was tested using Chi-square.
The autumn geographical distribution of bluefish was examined by age-class. Four age-classes, age 0 , 1,2 and $3+$ (fish age 3 or older), were plotted by year and by all years combined. Due to the relative inefficiency of a bottom trawl as a sampling gear for bluefish, no attempt was made to quantify bluefish abundance geographically other than recording their simple presence.

\section{Results}

A total of 3334 bluefish was sampled during NEFSC autumn bottom trawl surveys (Table 1). Catches occurred from Cape Hatteras, NC, to Georges Bank and Cape Cod Bay, MA. Lengths ranged from $3 \mathrm{~cm}$ to $88 \mathrm{~cm}$; there were 1571 males, 1483 females, and 457 were of unknown sex. The age range was between 0 and 12 years. Aging precision was determined to be about $97 \%$ with no discernible bias, based upon an exercise in which an experienced second age reader independently examined 2711 samples (Salerno, MS 1999).

Semi-logarithmic modeling of bluefish growth data resulted in highly significant relationships $\left(r^{2}=\right.$ 0.952 ) between length and age by sex and by year for both sexes combined (Table 2), indicating a strong functional relationship between length and age (Sokal and Rohlf, 1995). The results of the tests for heterogeneity of slopes revealed no significant differences in growth between sexes $(p=0.5630)$ nor in inter-annual growth $(p=0.7956)$ over the study 
TABLE 1. The number of bluefish age samples collected in the NEFSC autumn bottom trawl survey program by year.

\begin{tabular}{ll}
\hline \hline Year & $n$ \\
\hline 1985 & 405 \\
1986 & 271 \\
1987 & 281 \\
1988 & 176 \\
1989 & 318 \\
1990 & 284 \\
1991 & 162 \\
1992 & 265 \\
1993 & 145 \\
1994 & 391 \\
1995 & 359 \\
1996 & 277 \\
Total & 334 \\
\hline
\end{tabular}

period.

The estimated von Bertalanffy growth parameters for sexes combined (Fig. 2) were $L_{\text {inf }}=87.2 \mathrm{~cm} \pm 1.6$, $k=0.26 \pm 0.01$, and $t_{0}=-0.93 \pm 0.03\left(r^{2}=0.985\right)$. Mean incremental growth was greatest in the first two years of life (Fig. 3). During this time bluefish add 13-18 cm of body length each year. Between the second and third year, incremental growth decreased to $8-12 \mathrm{~cm}$, and to $3-5 \mathrm{~cm}$ in the fourth and subsequent years.

Analysis of maturity at length data generated the

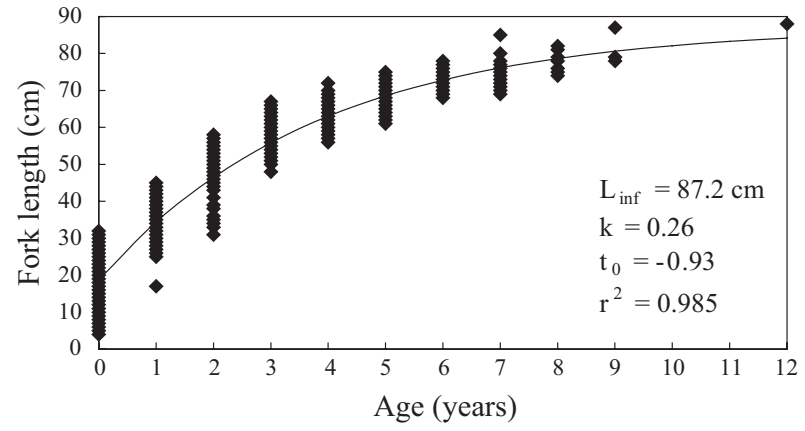

Fig. 2. The von Bertalanffy growth curve for bluefish, sexes combined, collected during the NEFSC autumn bottom trawl survey program, 1985-96.

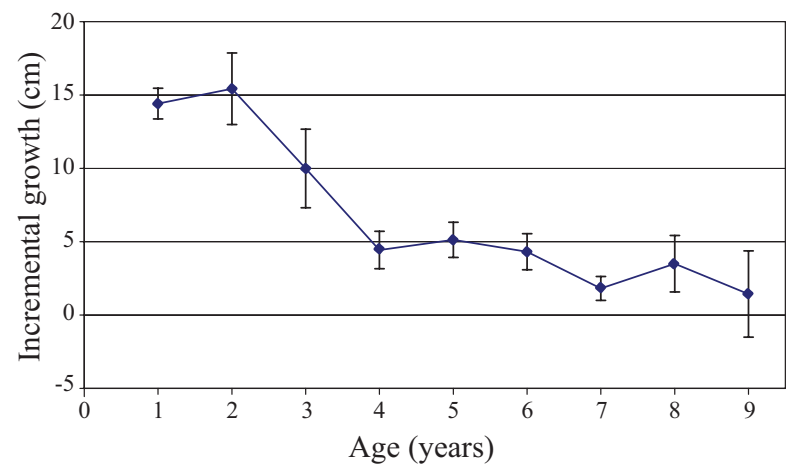

Fig. 3. Incremental growth for bluefish, sexes combined, using mean length-at-age for all fish collected during the NEFSC autumn bottom trawl survey program, 1985-96.

TABLE 2. Results of semi-logarithmic regression modeling of length-age data for bluefish by sex and by year.

\begin{tabular}{lcccc}
\hline \hline Regression & Slope $(\mathrm{b})$ & Intercept (a) & $r^{2}$ & Probability \\
\hline male (1985-96) & 22.7 & 29.1 & 0.984 & $<0.01$ \\
female (1985-96) & 22.7 & 29.1 & 0.984 & $<0.01$ \\
$1985^{*}$ & 23.3 & 31.3 & 0.975 & $<0.01$ \\
$1986^{*}$ & 21.5 & 30.4 & 0.987 & $<0.01$ \\
$1987^{*}$ & 21.8 & 31.1 & 0.972 & $<0.01$ \\
$1988^{*}$ & 24.2 & 27.5 & 0.970 & $<0.01$ \\
$1989^{*}$ & 21.4 & 32.1 & 0.975 & $<0.01$ \\
$1990^{*}$ & 21.6 & 31.8 & 0.972 & $<0.01$ \\
$1991^{*}$ & 20.6 & 31.8 & 0.983 & $<0.01$ \\
$1992^{*}$ & 22.4 & 28.4 & 0.985 & $<0.01$ \\
$1993^{*}$ & 20.6 & 32.1 & 0.968 & $<0.01$ \\
$1994^{*}$ & 22.8 & 30.1 & 0.982 & $<0.01$ \\
$1995^{*}$ & 21.3 & 30.5 & 0.962 & $<0.01$ \\
$1996^{*}$ & 21.0 & 29.2 & 0.952 & \\
\hline
\end{tabular}

* sexes combined 
following probit functions:

$$
\begin{aligned}
& y+5=(-4.97+0.15 x) \text { for females and } \\
& y+5=(-6.19+0.18 x) \text { for males }
\end{aligned}
$$

where $y=$ proportion mature, and

$x=$ length.

Calculated and observed proportions of mature bluefish by length and associated $95 \%$ confidence intervals are presented in Fig. 4 . The $L_{50}$ (median size at maturity) was $33.9 \mathrm{~cm}$ and $33.4 \mathrm{~cm}$ for males and females, respectively. Observed proportions at age (Table 3) showed that bluefish maturation occurs between 1 and 2 years for both sexes; calculated values of $A_{50}$ (median age at maturity) from probit analysis were 1.2 years for males and 1.1 years for females. The probit model provided statistically significant fits $(p<0.01)$ for all analyses.

Autumn geographical distribution of bluefish differed with age-class (Fig. 5). Age 0 and 1 bluefish were distributed mainly inshore from North Carolina to Massachusetts. Age 2 were found both inshore from the Virginia Peninsula to Massachusetts and offshore as far east as the Great South Channel. Some age 3+ fish were found inshore from Maryland to Massachusetts, but most 3 years and older were predominately found offshore and as far east as the northeast peak of Georges Bank. No shift in distribution was observed for any age-class during the study period.

\section{Discussion}

The maximum fork length of $88 \mathrm{~cm}$ observed in this study is within the range reported by Lassiter (MS 1962) of $81.2 \mathrm{~cm}$, Wilk and Walford (unpublished data; reported in Wilk, 1977) of $86 \mathrm{~cm}$, Chiarella and Conover (1990) of $88 \mathrm{~cm}$, and Lund and Maltezos (1970) of $95 \mathrm{~cm}$, all of which are in turn comparable to the maximum length of about 3.5 feet $(\sim 107 \mathrm{~cm})$ reported by Bigelow and Schroeder (1953). These lengths, however, are less than the maximum lengths reported in U.S. Marine Recreational Fishery Statistics Survey database: between 1984 and 1996, the maximum lengths for bluefish landed by recreational fisherman were between 96 and $120 \mathrm{~cm}^{1}$. Fowler (1936) reported the maximum length for bluefish off West Africa at $116 \mathrm{~cm}$, and Smith (1949) reported lengths over 4 feet (greater than $120 \mathrm{~cm}$ ) off South Africa.
The age 12 bluefish observed in this study is among the oldest reported for the region. Comparable maximum ages in other studies include age 11 (Terceiro and Ross, 1993), age 12 (Chiarella and Conover, 1990), and age 14 Wilk and Walford, (unpublished data; reported in Wilk, 1977). The maximum age recorded by Wilk (1977) in a sample of more than 25000 fish from Florida to Rhode Island, and by Hamer (MS 1959) was 9 years. Lassiter's (MS 1962) oldest reported bluefish from North Carolina was 8 years, Barger's (1990) oldest from the Gulf of Mexico was also 8 years, and Richards (1976) reported 7 years as the maximum age from Long Island Sound.

The similarity between male and female growth rates concurs with other studies, which analyzed bluefish growth by sex. Bluefish from the New York Bight (Hamer, MS 1959), North Carolina (Lassiter, MS 1962), Long Island Sound (Richards, 1976), the Gulf of Mexico and off the U.S. south Atlantic coast (Barger, 1990) all showed no appreciable growth differences between sexes.

The lack of inter-annual differences in growth during the study period suggests that bluefish growth may be independent of stock size. The absence of increased growth rates during a marked decrease in abundance in the 1990 s seems to imply that bluefish growth is maintained at or near the maximum under all stock conditions. This phenomenon may relate to the feeding ecology of bluefish. The wide variety of prey items that have been found in bluefish stomachs (Wilk, 1977) indicates they are opportunistic feeders. Lassiter (MS 1962) showed that, in North Carolina, the predominance of prey items in the stomach content was dependent on the time of the year, however, even on a monthly basis, a variety of fish and invertebrate species were found. Fluctuations in annual abundance of any one prey item would not appear to have a serious impact on the feeding patterns of bluefish.

The von Bertalanffy growth parameters derived in this study are most consistent with the growth parameters calculated by Wilk and Walford (unpublished data; reported in Wilk, 1977) (Table 4). The discrepancies with the other studies can be explained in part by the maximum recorded length of the bluefish sampled in each study. Larger maximum lengths increase the estimation of $L_{i n f}$, which results in a lower estimation of $k$ due to the inverse relationship between $L_{\text {inf }}$ and $k$ (Gallucci and Quinn, 1979). The work of Lassiter (MS 1962) with spring-

1 Personal communication from the National Marine Fisheries Service, Fisheries Statistics and Economics Division. 

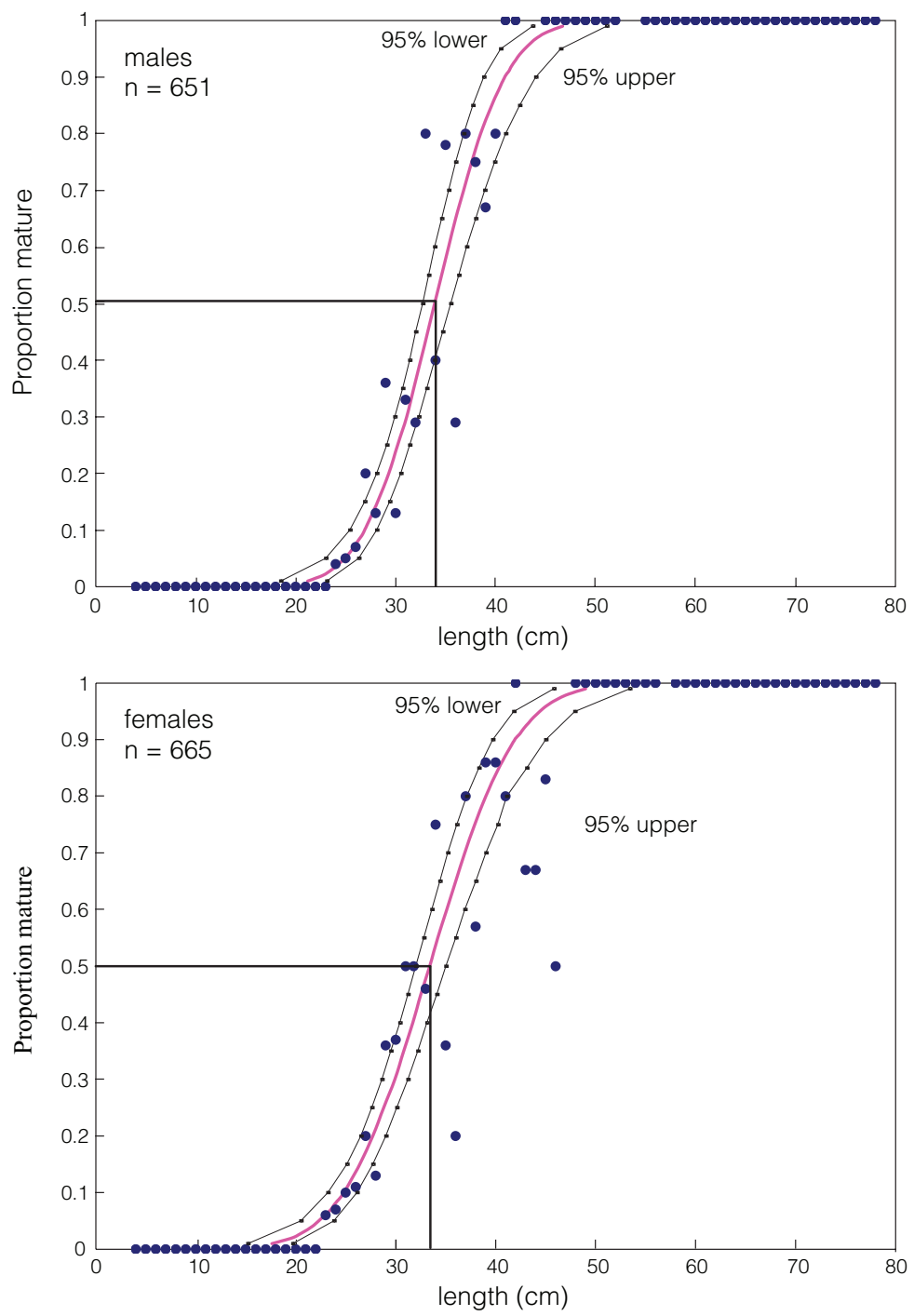

Fig. 4. Calculated and observed (*) proportion mature at length for male and female bluefish sampled during the NEFSC autumn bottom trawl survey program, 1993-96.

TABLE 3. Observed proportion mature at age based on macroscopic examination of bluefish gonads conducted during the NEFSC autumn bottom trawl survey program, 199396 (males $n=667$; females $n=718$ ).

\begin{tabular}{lccc}
\hline \hline & \multicolumn{3}{c}{ Proportion mature } \\
\cline { 2 - 4 } Age & Males & Females & Sexes Combined \\
\hline 0 & 0.00 & 0.00 & 0.00 \\
1 & 0.38 & 0.44 & 0.41 \\
2 & 0.94 & 1.00 & 0.98 \\
3 & 1.00 & 1.00 & 1.00 \\
4 & 1.00 & 1.00 & 1.00 \\
5 & 1.00 & 1.00 & 1.00 \\
6 & 1.00 & 1.00 & 1.00 \\
7 & 1.00 & 1.00 & 1.00 \\
8 & 1.00 & 1.00 & 1.00 \\
\hline
\end{tabular}



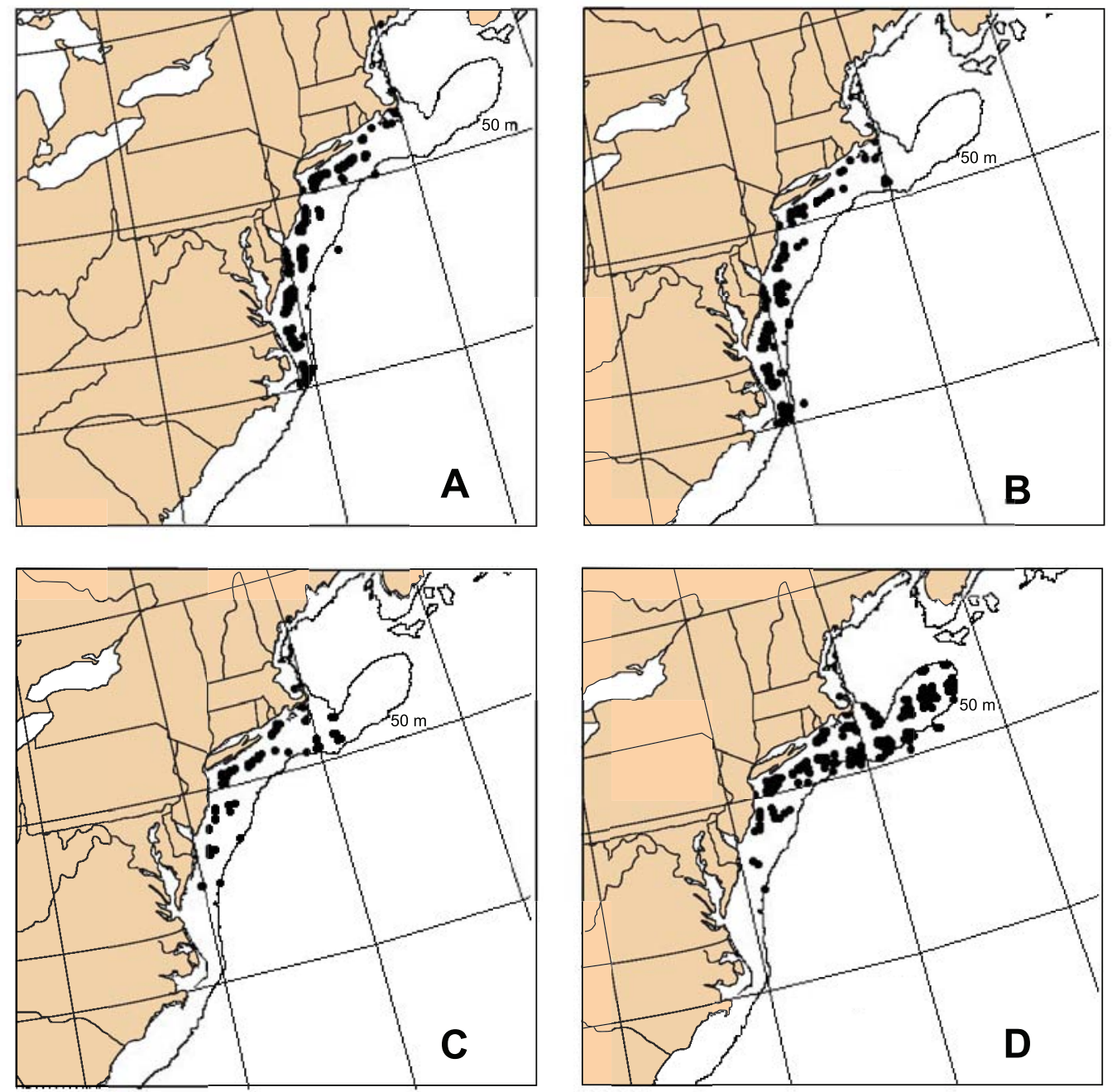

Fig. 5. Spatial distribution by age-class for bluefish caught during the NEFSC autumn bottom trawl survey program, 1985-96. (A) age 0, (B) age 1,(C) age 2, and (D) age $3+$.

TABLE 4. Von Bertalanffy growth parameters calculated for bluefish from various regions of its distribution along the east coast of the United States.

\begin{tabular}{|c|c|c|c|c|c|c|}
\hline Region & Age structure & $L_{i n f}(\mathrm{~cm})$ & $k$ & $t_{0}$ & $N$ & Reference \\
\hline $\begin{array}{l}\text { Northest Region } \\
(\mathrm{ME}-\mathrm{NC})\end{array}$ & scales & 87.2 & 0.26 & -0.93 & 3334 & Present study \\
\hline Florida-Rhode Island & scales & 87.9 & 0.24 & -0.11 & $>25000$ & $\begin{array}{l}\text { Wilk \& Walford (unpublished data; } \\
\text { reported in Wilk, 1977)" }\end{array}$ \\
\hline Long Island Sound & scales & 79.5 & 0.32 & -0.08 & 64 & Richards (1976) \\
\hline $\begin{array}{l}\text { North Carolina } \\
\text { (spring spawned) }\end{array}$ & scales & 67.5 & 0.34 & -0.25 & 290 & Lassiter (1962) \\
\hline $\begin{array}{l}\text { North Carolina } \\
\text { (summer spawned) }\end{array}$ & scales & 128.5 & 0.10 & -1.37 & 154 & Lassiter (1962) \\
\hline Gulf of Mexico & otoliths & 94.4 & 0.18 & -1.03 & 1190 & Barger (1990) \\
\hline $\begin{array}{l}\text { Florida Atlantic } \\
\text { Coast }\end{array}$ & otoliths & 101.9 & 0.10 & -2.49 & 842 & Barger (1990) \\
\hline
\end{tabular}


and summer-spawned bluefish in North Carolina best illustrates this relationship. Asymptotic lengths for these fish were 67.5 and $128.5 \mathrm{~cm}$, respectively, and the corresponding growth coefficients were 0.34 and 0.10 (Table 4).

Maturity analyses suggest that, despite decreases in bluefish abundance, recent maturation patterns have not changed from those observed by Wilk (1977) for fish collected during 1963-68. Wilk (1977) reported about $50 \%$ of age 1 fish were mature and full maturity was attained by age 2 . Although not specifically addressed by Wilk (1977) or this study, it is possible to conclude that, of age 1 fish, those, which mature are the prodigy of a spring-spawning event, having enjoyed greater growth as young-of-the-year fish, and those which remain immature at age 1 belong to the summer-spawned cohort. However, until bluefish spawning seasonality is resolved, this remains an issue for future research.

The spatial distributions presented in this study are consistent with the published literature on bluefish distribution for late summer. Concentrations of juveniles and adults are greatest from northern North Carolina to Cape Cod in the late summer (Kendall and Walford, 1979; Oliver et al., 1989). During this time, the water temperature was within the preferred range for bluefish at $19^{\circ}$ to $22^{\circ} \mathrm{C}$ (Wilk, 1977). The occurrence of bluefish in large numbers north of North Carolina persist until the late autumn when water temperatures decease to approximately $13^{\circ}$ to $15^{\circ} \mathrm{C}$ (Lund and Maltezos, 1970).

The distribution by age-class reflects the findings of Lund and Maltezos (1970): fish that are up to about $50 \mathrm{~cm}$ are generally found close to shore and larger fish are generally found in deeper water farther offshore. In this study, fish lengths up to $50 \mathrm{~cm}$ would include age-class 0 , age-class 1 and some of the ageclass 2 fish. Age-class 0 fish that were found offshore could have been juveniles that had not yet moved inshore to the estuaries (Kendall and Walford, 1979). Age-class 1 and 2 fish found offshore could have been mature fish that had not yet returned inshore after spawning (Oliver et al., 1989). The occurrence of ageclass $3+$ fish inshore might reflect fish that had moved inshore after the spawning period to feed (Lund and Maltezos, 1970). The persistent presence of older ageclass fish offshore and the lack of any observed shift in distribution of these fish during this study period do not seem to support the hypothesis put forth by Crecco (MS 1996), which states that since the early- 1980s the adult bluefish population distribution has been displaced offshore ( $>3$ miles). It is important to note that the gear used during NEFSC bottom trawl surveys may not provide optimal sampling of a fastswimming, pelagic species such as bluefish; indeed, the likelihood exists that larger specimens are caught in the act of net-feeding. However, while catches of larger, older bluefish may be biased, we conclude that the overall spatial distribution patterns reported by this study should not be affected.

\section{Acknowledgements}

We thank L. O'Brien and M. Terceiro from the National Marine Fisheries Service, Northeast Fisheries Science Center, and S.A. Moss and R.W. Griffith from the University of Massachusetts, Dartmouth, for their critical reviews of this manuscript. This manuscript was part of a thesis submitted by the primary author in partial fulfillment of the requirements for the M.S. degree in marine biology at the University of Massachusetts, Dartmouth.

\section{References}

AZAROVITZ, T. R. 1981. A brief historical review of the Woods Hole Laboratory trawl survey time series. In: Doubleday, W.G. and Rivard, D. (eds.). Bottom trawl surveys. Can. Spec. Publ. Fish. Aquat. Sci., 58: 62-67.

BARGER, L. E. 1990. Age and growth of bluefish, Pomatomus saltatrix, from the northern Gulf of Mexico and U.S. South Atlantic coast. Fish. Bull., 88(4): 805809.

BERTALANFFY, L. VON. 1938. A quantitative theory of organic growth (inquiries on growth laws. II.). Human Biology, 10: 181-213.

BIGELOW, H. B., and W. C. SCHROEDER. 1953. Fishes of the Gulf of Maine. U.S. Fish. Wild. Serv., Fish. Bull., 74: 382-389.

BOWERING, W. R., and W. B. BRODIE. 1984. Distribution of witch flounder in the northern Gulf of St. Lawrence and changes in its growth and sexual maturity patterns. North Am. J. Fish. Manag., 4: 399-413.

BOWERS, A. B. 1960. Growth of the witch (Glyptocephalus cynoglossus) in the Irish Sea. ICES J. Cons., 25: 168-176.

BRIGGS, J. C. 1960. Fishes of world-wide (circumtropical) distribution. Copeia, 3: 171-180.

BURNETT, J, L. O'BRIEN, R. K. MAYO, J. A. DARDE, and M. BOHAN. MS 1989. Finfish maturity sampling and classification schemes used during Northeast Fisheries Center bottom trawl surveys. NOAA Tech. Mem., NMFSF/NEC-76, $14 \mathrm{p}$.

CHIARELLA, L. A., and D. O. CONOVER. 1990. Spawning season and first-year growth of adult bluefish from the New York Bight. Trans. Am. Fish. Soc., 119: 455-462. 
CRECCO, V. MS 1996. Evidence of offshore displacement of Atlantic coast bluefish based on commercial landings and fishing effort. Report to the SAW Coastal/Pelagic Subcommittee, $26 \mathrm{p}$.

FINNEY, D. J. 1971. Probit Analysis. $3^{\text {rd }}$ ed. Cambridge University Press, $333 \mathrm{p}$.

FINUCANE, J. H., H. A. BRUSHER, and L. A. COLLINS. 1980. Spawning of bluefish, Pomatomus saltator [sic], in the northeastern Gulf of Mexico. Northeast Gulf Sci., 4: $57-59$.

FOWLER, H. W. 1936. The Marine Fishes of West Africa. Vol. LXX. Part II. The American Museum of Natural History. New York. 1493 p.

GALLUCCI, V. F., and T. J. QUINN II. 1979. Reparameterizing, fitting, and testing a simple growth model. Trans. Amer. Fish. Soc., 108: 14-25.

HAMER, P. E. MS 1959. Age and growth studies of bluefish (Pomatomus saltatrix) of the New York Bight. M.S. thesis, Rutgers Univ., New Brunswick, New Jersey. 27 p.

HARE, J. A., and R. K. COWEN. 1993. Ecological and evolutionary implications of the larval transport and reproductive strategy of bluefish Pomatomus saltatrix. Mar. Ecol. Prog. Ser., 98: 1-16.

KENDALL, A. J., Jr., and L. A. WALFORD. 1979. Sources and distribution of bluefish, Pomatomus saltatrix, larvae and juveniles off the east coast of the United States. Fish.Bull., 77(1): 213-227.

LASSITER, R. R. MS 1962. Life history aspects of the bluefish, Pomatomus saltatrix, from the coast of North Carolina. M.S. thesis, North Carolina State College, Raleigh, North Carolina. $103 \mathrm{p}$.

LUND, W. A., and G. C. MALTEZOS. 1970. Movements and migrations of the bluefish, Pomatomus saltatrix, tagged in waters of New York and southern New England. Trans. Amer. Fish. Soc., 99: 719-725.

MCBRIDE, R. S. and D. O. CONOVER. 1991. Recruitment of young-of-the-year bluefish Pomatomus saltatrix to the New York Bight: variation in abundance and growth of spring- and summer-spawned cohorts. Mar. Ecol. Prog. Ser., 78: 205-216.

MORGAN, M. J., and J. M. HOENIG. 1997. Estimating maturity-at-age from length stratified sampling. $J$. Northw. Atl. Fish. Sci., 21: 51-63.

NEFSC. MS 1997. Report of the $23^{\text {rd }}$ Northeast Regional
Stock Assessment Workshop (23 $\left.{ }^{\text {rd }} \mathrm{SAW}\right)$. NEFSC Ref. Doc., No. 97-05, 191 p.

NYMAN, R. M., and D. O. CONOVER. 1988. The relation between spawning season and the recruitment of youngof-the-year bluefish, Pomatomus saltatrix, to New York. Fish. Bull. U.S., 86: 237-250.

O'BRIEN, L., J. BURNETT, and R. K. MAYO. 1993. Maturation of nineteen species of finfish off the Northeast Coast of the United States, 1985-1990. NOAA Tech. Rep., NMFS, 113, 66 p.

OLIVER, J. D., M. J. VAN DEN AVYLE, and E. L. BOZEMAN, Jr. 1989. Species profile: life histories and environmental requirements of coastal fishes and invertebrates (South Atlantic. Bluefish. U.S. Fish. Wild. Serv. Biol. Rep. 82(11.96), U.S. Army Corps of Engineers, $14 \mathrm{p}$.

PENTTILA, J., F. NICHY, J. ROPES, L. M. DERY, and A. JEARLD. 1988. Methods and Equipment. In: Age determination methods for Northwest Atlantic species. Penttila, J. and Dery, L.M. (eds.). NOAA Tech. Rep., NMFS, 72, $135 \mathrm{p}$.

RICHARDS, S. W. 1976. Age, growth and food of the bluefish (Pomatomus saltatrix) from east-central Long Island Sound from July through November 1975. Trans. Am. Fish. Soc., 105: 207-209.

SALERNO, D. J. MS 1999. A study on age, growth, maturity and distribution of the bluefish, Pomatomus saltatrix (Linnaeus), from the Northeast Region of the United States with an analysis of age-length key data. M.S. thesis, University of Massachusetts - Dartmouth, North Dartmouth, Massachusetts, $103 \mathrm{p}$.

SAS INSTITUTE. 1988. SAS/STAT ${ }^{\mathrm{TM}}$ User's Guide. Release 6.03 ed. SAS Institute. Cary, North Carolina, 1028 p.

SMITH, J. L. B. 1949. The Sea Fishes of Southern Africa. Central News Agency, Ltd. South Africa, 550 p.

SOKAL, R. R., and F. J. ROHLF. 1995. Biometry. $3^{\text {rd }}$ ed. W.H. Freeman and Company. New York, 887 p.

TERCEIRO, M., and J. L. ROSS. 1993. A comparison of alternative methods for the estimation of age from length data for Atlantic coast bluefish (Pomatomus saltatrix). Fish. Bull., U.S., 91: 534-549.

WILK, S. J. 1977. Biological and fisheries data on bluefish, Pomatomus saltatrix (Linnaeus). NOAA/NMFS, Sandy Hook Lab. Tech. Ser. Rep., 11, 54 p. 